\title{
REINTERPRETACIÓN DEL ESPECTADOR IMPARCIAL: IMPERSONALIDAD UTILITARISTA O RESPETO A LA DIGNIDAD
}

\author{
María A. Carrasco \\ Facultad de Filosofía \\ Pontificia Universidad Católica de Chile \\ mcarrasr@uc.cl
}

\begin{abstract}
RESUMEN: Durante la Ilustración escocesa se legitimó la "perspectiva del espectador imparcial" como garantía de juicios morales imparciales. Esta escuela de pensamiento se ha considerado tradicionalmente como la antesala del utilitarismo. Sin embargo, actualmente se sostiene que, aunque Hutcheson y Hume sí son protoutilitaristas, la teoría de Smith es la primera gran crítica al utilitarismo. En este ensayo atribuyo esta diferencia a la posición desde la que juzga el espectador - tercera o segunda persona - de la que se derivan estructuras metaéticas distintas que condicionan, entre otras cosas, el significado de la noción de imparcialidad.
\end{abstract}

PALABRAS CLAVE: sistemas morales, perspectiva de la segunda persona, perspectiva de la tercera persona, Ilustración escocesa, Adam Smith

SUMMARY: During the Scottish Enlightenment, the "point of view of the spectator" was considered to be the adequate standpoint from where to make impartial moral judgments. This school of thought has often been seen as anticipating Utilitarianism. However, many interpreters are now saying that, despite their similar approaches to ethics, Hutcheson's and Hume's theories are proto-utilitarian while Smith's is not. Indeed, Smith was the first important critic of Utilitarianism. In this paper I provide further reasons for Smith's critical attitude to Utilitarianism by tracing it back to his specific account of the position of the impartial spectator: either a third-person or a second-person standpoint. This position generates different meta-ethical structures that determine, among other things, the meaning of the notion of impartiality.

KEY WORDS: moral systems, second-person perspective, third-person perspective, Scottish Enlightenment, Adam Smith

La figura de un "espectador imparcial" como juez de la moralidad de las acciones fue una novedosa contribución de los filósofos de la Ilustración escocesa para la teoría ética moderna. ${ }^{1}$ Aunque la idea ya rondaba en los círculos intelectuales de su tiempo, Francis Hutcheson, el padre de este movimiento intelectual (Hutcheson 2007, p. ix), fue el primero en adoptar formalmente esta original aproximación ética, cambiando la perspectiva del juicio moral para situarla en la que ofrecería un espectador de los actos de otro. David Hume y

${ }^{1}$ La expresión espectador imparcial se popularizó con Adam Smith, pero Hutcheson y Hume ya hablaban de "observador", "juez", etc., refiriéndose a la misma perspectiva. 
Adam Smith, también grandes exponentes de esta corriente, adoptaron esa perspectiva en sus éticas, asumiendo que la distancia crítica de un espectador desinteresado podía garantizar la imparcialidad en los juicios morales (Broadie 2006, pp. 158-159). De este modo, estos filósofos sentimentalistas consolidaron "el punto de vista del espectador" como una alternativa legítima para avalar la objetividad de los juicios morales.

Junto a esta perspectiva, dichos autores compartieron numerosas características en sus respectivas propuestas, y por largo tiempo éstas se interpretaron de modo similar. Sin embargo en las últimas décadas, tras el fuerte resurgimiento que ha tenido el estudio de la Teoría de los Sentimientos Morales de Adam Smith, ${ }^{2}$ se ha constatado que bajo sus evidentes similitudes sus teorías esconden también profundas divergencias. Los ilustrados escoceses por siglos fueron considerados los precursores inmediatos del utilitarismo moderno, pero en la actualidad, no sin cierta sorpresa, se ha ido expandiendo la idea de que, si bien los sistemas de Hutcheson y Hume son en efecto protoutilitaristas, el de Smith en cambio podría considerarse una de las primeras grandes (proto)críticas de esa teoría (Fleischacker y Brown 2010, p. 1). ${ }^{3}$ La pregunta es, entonces, cómo desde el mismo tronco sentimentalista y espectatorial pudieron desprenderse éticas tan contrapuestas e incompatibles.

Mi tesis es que la perspectiva del espectador no es unívoca, en el sentido de que dicho espectador puede colocarse en distintas posiciones para realizar el juicio, y que, dependiendo de esa posición (o desde dónde se juzga), se determinará la estructura metaética de una teoría. Esta estructura, a su vez, condicionará cualquier teoría moral que la utilice, tanto respecto del objeto del juicio, su justificación, como también - en lo que me detendré particularmente en este artículo - lo que se entenderá por imparcialidad en cada ética. La tesis puede ilustrarse con las mismas propuestas de los escoceses. Mientras Hutcheson y Hume sitúan al espectador en una posición "de la tercera persona", generando una estructura que llamaré dicotómica y que tiende a deslizarse hacia el utilitarismo; Smith lo ubica en una posición "de la segunda persona", 4 produciendo una estructura

\footnotetext{
${ }^{2}$ En adelante TMS. Se citará del modo canónico, esto es parte/sección/capítulo/parágrafo.

${ }^{3}$ Aunque hace décadas se empezó a cuestionar la similitud de las teorías de estos autores ( $c f r$. Raphael 1972-1973), la interpretación se ha ido profundizando y extendiendo con gran intensidad en los últimos años.

${ }^{4}$ Darwall (2006) dice también que Smith fue el primer filósofo "de la segunda persona" (p. 46).
} 
que denominaré "ética de la segunda persona", la cual, entre otras características, la vuelve incompatible con el utilitarismo.

En este artículo analizaré las causas que provocan que la distinta posición del espectador imparcial configure tan diversas estructuras metaéticas, y mostraré por qué el "espectador en segunda persona" - como el que Smith propone - se ha vuelto tan atractivo para el debate ético contemporáneo (Sen 2013, p. 592).

Comenzaré con una breve descripción de las diferencias de las éticas sentimentalistas-espectatoriales de estos autores. Luego explicaré a qué me refiero con el "espectador en tercera persona" de Hutcheson y Hume y las consecuencias de esta postura para la estructura metaética de sus sistemas. En tercer lugar contrastaré ese espectador con el de Smith, explicando cómo el cambio de posición del mismo impacta en la estructura de su teoría. En la penúltima parte analizaré la importancia de la posición del espectador para lo que se entiende por imparcialidad en cada uno de estos sistemas; y terminaré apuntando a otros aspectos de la "ética de la segunda persona" que autores contemporáneos han venido recogiendo y valorando como posibles contribuciones para la construcción de un nuevo paradigma moral que supere las carencias de los sistemas modernos.

\section{Sentimentalismo-espectatorial}

Durante la Ilustración escocesa, Francis Hutcheson fue el precursor de las éticas sentimentalistas-espectatoriales $-o$ aquellas en las cuales el juicio moral es determinado por las respuestas afectivas de un espectador imparcial (Darwall 1997, p. 80) - al definir formalmente la virtud como la percepción de una cualidad en el agente: "La virtud se llama amable y agradable en cuanto produce buena voluntad y amor de los espectadores hacia los agentes" (Hutcheson 2004, p. 218). Con ello dio un giro al punto de vista desde el que se juzga una acción para situarla en el que ofrecería un espectador de los actos de otro.

Hume y Smith siguieron esta aproximación a la ética, aunque entendiendo cosas muy distintas por "sentimentalismo" y por "espectador". Respecto de lo primero, Hutcheson postulaba la existencia de un "sentido moral", un sentido interno - análogo a los externosque capta de modo inmediato las cualidades morales de los agentes y las des/aprueba con independencia de la voluntad del espectador (Hutcheson 2004, p. 100). Hume rechaza la existencia de un "sentido moral" como lo entendía Hutcheson, pero reafirma que "toda la 
moralidad depende de los sentimientos". ${ }^{5}$ En su teoría la "simpatía" tiene el papel central en la generación de los sentimientos morales. Por simpatía Hume entiende un poderoso principio de comunicación de sentimientos por el que las personas "se contagian" sus pasiones (Tr 3.3.3.5). ${ }^{6}$ Por último, Smith alaba a Hutcheson afirmando que fue el primero en descubrir que las distinciones morales se captan por el sentido y el sentimiento inmediatos (TMS VII.iii.2.9); pero rechaza tanto el "sentido moral" de su antecesor (TMS VII.iii.3.4) como la noción y función de la simpatía en Hume (TMS VII.iii.3.17). ${ }^{7}$ Para Smith ésta también tiene un papel principal en los juicios morales, pero él la define como la identificación imaginativa del espectador con el agente; un cambio de posiciones imaginario (TMS VII.3.1.4) o una forma de "proyectarse a sí mismo dentro del carácter y la situación del otro para poder aprehender lo que el otro está sintiendo" (Broadie 2006, pp. 162-163). Fleischacker sintetiza la diferencia diciendo que Hume postula una "simpatía-contagio" mientras que Smith una “simpatía-proyección" (Fleischacker 2012, p. 276).

Junto con las divergencias en sus sentimentalismos, la noción del "espectador" de los escoceses también difiere. Aunque los tres otorgaron prioridad al punto de vista del espectador no lo definieron de igual manera ni lo situaron en la misma posición. Este último punto, que probablemente los escoceses no advirtieron, es el que de acuerdo con mi tesis cambia la estructura y el carácter de una teoría moral.

La principal diferencia se da entre la posición desde la que juzga el espectador en las éticas de Hutcheson y Hume, por un lado; y la del espectador en la ética de Smith. Para los dos primeros el espectador estaría situado en lo que hoy en día se llama posición "de la tercera persona". Es decir, el espectador observa "desde fuera", no está involucrado con el objeto ni la situación juzgada; es, por así decirlo, un espectador externo. En contraste, el espectador que describe Smith está en una posición "de la segunda persona". El espectador no se ubica fuera de la situación juzgada sino que participa en ella, interactúa (de manera real o virtual) con los agentes y es personalmente afectado por la situación. El espectador en segunda

${ }^{5}$ Hume, A Treatise on Human Nature 3.2.5.4. En adelante Tr, y lo citaré de modo canónico, i.e., libro/sección/capítulo/parágrafo.

${ }^{6}$ Se discute si Hume se refiere a un contagio de tipo mecánico (como "las cuerdas de un instrumento", según su metáfora) o a una inferencia del espectador (Tr 3.3.1.7). No obstante, hay consenso en que, al margen de su modo de operación, la función de la simpatía en Hume no cambia esencialmente. Véanse Fleischacker 2012, y Debes 2007a y 2007b.

${ }^{7}$ Véanse también Fleischacker 2012, p. 291 y Darwall 2006, p. 129. 
persona se relaciona con los agentes; "entra" al mundo y juzga desde dentro.

\section{Hutcheson y Hume: el espectador externo y la estructura dicotómica}

Según afirma Alexander Broadie, Hutcheson y Hume emularon el modelo "newtoniano" y colocaron al espectador fuera del fenómeno observado (Broadie 2003, p. 64). Hutcheson, en primer lugar, lo situó en personas reales, "sin vínculos especiales con ninguna de las partes [...] que no obtienen ningún beneficio con la decisión. [Que] no son más sabias ni mejores que los contendientes [pero que en ese caso concreto] pueden decidir más fácilmente lo que es más justo y equitativo" (Hutcheson 2007, p. 213). Los espectadores son personas comunes y corrientes pero que pueden ser imparciales porque, estando fuera de la situación juzgada, pueden aprehender cualidades sin ser personalmente afectados por ellas y porque el resultado del juicio les resulta indiferente. Cada espectador juzga con su propio sentido moral mas, dada su común naturaleza humana, todos se complacen con la aprehensión de las mismas cualidades (Hutcheson 2004, p. 148). En concreto, lo que complace al sentido moral es la virtud de la benevolencia o la intención desinteresada de promover la felicidad más extensiva o el mayor bien público (Hutcheson 2005, vol. 1, p. 69). Para Hutcheson la benevolencia no es la única virtud que existe, no obstante, en última instancia, sí las subsume a todas (Norton y Kuehn 2006, p. 954). Por último, en este sistema la razón no tiene más que una función auxiliar o instrumental para el juicio moral; sirve para encontrar el mejor medio para el fin propuesto por el sentido moral (Hutcheson 2002, p. 39), calcula, compara, etc., pero "no entra en el discernimiento moral" (Hutcheson 2005, vol. 2., p. 25).

Hume también sitúa al espectador en una posición externa o de tercera persona. La diferencia con Hutcheson es que no atribuye el punto de vista imparcial al sentido moral de observadores reales, sino que lo construye íntegramente desde la interacción social. Para Hume la simpatía, o el principio que nos hace sentir las mismas pasiones que observamos en los demás, es condición para el juicio moral, pero advierte que nos resulta mucho más fácil simpatizar con quienes son más cercanos o parecidos a nosotros ( $\operatorname{Tr}$ 3.3.3.4). La simpatía será siempre parcial, pues hay actos que nos "aparecen igualmente virtuosos y se recomiendan igualmente a la estima de un espectador juicioso. Pero la simpatía varía sin que varíe la estima. 
Nuestra estima, por tanto, no procede de la simpatía" (Tr 3.3.1.14). Por ello, si ella rigiera la convivencia social viviríamos en riesgo de permanente conflicto. De ahí que "para llegar a un juicio más estable [la naturaleza nos impulsa a fijar] un punto de vista más firme y general; y siempre, en nuestro pensamiento, nos ponemos en esa posición [y] corregimos la apariencia momentánea de las cosas" (Tr 3.3.1.15). Es decir, superamos nuestra parcialidad innata moviéndonos hacia una posición de consenso: la de un espectador que representa los estándares generales de la sociedad de los que dependen nuestros sentimientos morales ( $\operatorname{Tr}$ 3.3.1.30). El espectador, en este caso, no es una tercera persona real ni tampoco se identifica conmigo. Es una posición, un punto de vista común o perspectiva general donde debemos ubicarnos para realizar los juicios morales, que encapsula las convenciones propias de cada sociedad ( $c f r$. Tr 3.3.3.2). Es una posición externa tanto a mí misma como a la situación juzgada, cuya función es corregir las pasiones espontáneas de nuestra siempre parcial simpatía y así posibilitar el juicio imparcial. En definitiva, "Hume enfatiza la importancia del punto de vista general para la corrección de los sesgos subjetivos causados por la distorsión a la que la proximidad o contigüidad nos llevan" (Debes 2007b, p. 318). Desde esta posición las cualidades que complacen al espectador y por tanto se aprueban moralmente son aquellas que resultan agradables o útiles para el agente o para los demás (Tr 3.3.5.1). Como resume Fleischacker,

Hume separa rigurosamente la simpatía del juicio moral. El juicio moral consiste en nuestro reconocimiento de que las cualidades de una persona tienden a su felicidad o a la de los que la rodean [... ] La simpatía nos pone en la posición de sentir la aprobación moral, pero no es la que constituye dicha aprobación $(2012$, p. 275).

Por último, igual que para Hutcheson, la razón es también secundaria; sólo desempeña un papel auxiliar o instrumental para la realización del juicio ( $\operatorname{Tr}$ 3.1.1.6).

A pesar de las evidentes diferencias entre estas teorías, comparten un elemento que termina configurando una misma estructura metaética - que será la que utilizará el utilitarismo del que estos filósofos son precursores-: la posición que ocupa el espectador. Ambos sitúan al espectador en una posición de tercera persona, con lo que se establece un peculiar modelo ético que condiciona ciertas características de cualquier teoría normativa particular que lo utilice. Cuando el juicio 
moral se realiza desde la perspectiva de un espectador externo se genera lo que llamaré un sistema dicotómico, una estructura dual en la que, por un lado, se encuentra el espectador que juzga (y no es afectado por la situación); y por el otro, frente a él, el "todo" o el conjunto de los agentes potencialmente afectados por aquello que se juzga.

Ahora bien, el juicio realizado desde una perspectiva externa o de la tercera persona en un sentido limita, pero en otro también amplía la percepción del espectador (i.e., los elementos que puede considerar para realizar el juicio moral). La limita en cuanto desde fuera el espectador sólo puede percibir la expresión externa de las cualidades de los agentes. Para Hutcheson y para Hume la aprobación moral o complacencia del espectador depende de una cualidad del agente; pero la posesión de esa cualidad únicamente se comprueba cuando ella se ejercita y produce efectos. La cualidad, en sí misma, no es observable desde fuera. En consecuencia, la percepción del espectador externo está constitutivamente limitada: el observador sólo aprehende los efectos de esa cualidad, sus manifestaciones externas que serán, en la práctica, el verdadero objeto del juicio.

No obstante, en otro sentido, la perspectiva de la tercera persona amplía la percepción del espectador. Un espectador que está "fuera" de la situación juzgada puede ver el sistema como una totalidad, capturarlo en una única mirada. Y, en la medida en que es un espectador imparcial que debe considerar por igual a todos, verá en cada agente un ser que importa tanto como cualquier otro. Asimismo, dada esa visión global, el espectador también podrá percibir con facilidad el impacto que tienen las cualidades de los agentes sobre el "todo" o, como dice Hutcheson, "la tendencia de las acciones". En este último autor ello resulta particularmente claro cuando, sin saberlo, hace una de las primeras formulaciones del posterior principio de utilidad: "A igual grado de felicidad esperada de un acción, la virtud es proporcional al número de personas a que ésta se extienda" (Hutcheson 2004, p. 125).

Así es como la perspectiva del espectador en tercera persona configura una estructura dicotómica. Por un lado está el espectador indiferente que mira y juzga desde fuera; y por el otro, frente a sus ojos, el todo: un sistema compuesto por un agregado de agentes que "valen" exactamente igual. El espectador no necesita identificar a los agentes para juzgarlos, pues la única característica moralmente relevante (la que le complacerá y cuánto le complacerá) será la expresión de aquella cualidad definida con antelación como virtuosa. 
Algunas consecuencias que derivan de esta singular estructura y que determinarán a las teorías normativas que la usen son: (1) se requiere una definición a priori de las cualidades que se considerarán virtuosas, puesto que eso es lo que el espectador debe medir (o complacerse por); (2) el espectador sólo puede acceder a las cualidades expresadas por los agentes, y esta expresión (acción y consecuencias) se convierte en lo que determinará su juicio; (3) los agentes, en sí mismos, son partes de un todo, y el espectador será imparcial en cuanto los trate como "partes iguales". Llevado al extremo, y al no requerir agentes autoidentificados, éstos son susceptibles de ser vistos como recipientes anónimos de aquellas cualidades que se han definido como virtuosas; ${ }^{8}$ (4) debido a lo anterior, la imparcialidad puede, en esta perspectiva, confundirse con la impersonalidad. La imparcialidad en tercera persona es dar a cada uno (incluyéndose a sí mismo) exactamente igual importancia, con independencia de su posición en el mundo, ${ }^{9} \mathrm{o}$ - en la famosa formulación de Benthamque "cada uno cuenta como uno y nadie como más que uno". Imparcialidad implica igualdad, pero una igualdad formal que ignora los aspectos personales y contextuales que hacen a cada individuo único. Finalmente, (5) como el espectador en tercera persona sólo percibe la manifestación de las cualidades del agente y, de manera simultánea tiene también frente a sí al sistema como un todo, su juicio moral tenderá a realizarse midiendo el impacto o los efectos de la acción del agente en el todo. Esto conllevaría el razonamiento técnico en el juicio moral: el espectador puede cuantificar la virtud, graduar a los recipientes impersonales según sus propiedades y calcular su mérito sopesando "todos los factores que indiquen las consecuencias que un determinado acto puede tener para la humanidad como un todo" (Blackstone 1965, p. 70).

\footnotetext{
${ }^{8}$ Se trata de una crítica habitual al utilitarismo. Esta estructura dicotómica envuelve un concepto de imparcialidad del que B. Williams dice que "ve a las personas como lugares (posiciones) de sus respectivas utilidades [...] como los estanques de petróleo individuales en el análisis de consumo nacional de petróleo" (Sen y Williams 1982, p. 4). Esto es, recipientes anónimos, impersonales, donde cada uno cuenta como uno pero como "unos" intercambiables, sumables.

${ }^{9}$ Según Hutcheson el agente debe "dar a sus intereses exactamente el mismo peso que a los de los otros" (2004, p. 123). Slote afirma que en esta aproximación a la ética la justificación moral consiste en "un tipo particular de desapego de nuestro rol habitual de agentes en el mundo. Los juicios morales [...] se hacen mejor desde un punto de vista que se abstraiga de la identidad o individualidad del agente; desde un punto de vista que nos desvincule de cualquier agente particular y nos saque completamente del mundo" (1985, p. 101).
} 
En suma, situando al espectador en una posición de tercera persona, Hutcheson y Hume crean esta novedosa estructura metaética que, con independencia de su contenido normativo, favorece que los juicios se lleven a cabo midiendo las consecuencias de las acciones realizadas por agentes impersonales (no identificados) que carecen de los instrumentos teóricos para evitar el cálculo moral. De aquí que, con razón, a Hutcheson y a Hume se les pueda atribuir haber pavimentado el camino al utilitarismo: ese influyente sistema moderno que se construyó sobre esta estructura metaética y la llevó hasta sus últimas consecuencias. ${ }^{10}$

\section{Adam Smith y el punto de vista de la segunda persona}

Dentro del propio sentimentalismo-espectatorial Adam Smith rompe la estructura de sus predecesores y propone un modelo ético completamente distinto. Smith no parece advertir la magnitud de los cambios, pero, según se ha ido descubriendo en los últimos años, no sólo refuta el protoutilitarismo de sus contemporáneos sino que propone una interesante alternativa a ese modelo. De acuerdo con mi tesis, este giro se realiza por el cambio del punto de vista en el juicio moral desde la posición de un espectador en tercera persona a uno en segunda persona. Ello es posible gracias a dos grandes novedades en su teoría: la noción de simpatía mutua y la internalización del espectador imparcial. Así, Smith colapsa la estructura dicotómica y anula sus repercusiones respecto del objeto y justificación del juicio moral; cambia el papel de la razón y el significado del término imparcialidad.

\section{1. Simpatía mutua}

Un pasaje clave de la TMS para comprender la distinción entre el espectador en tercera y segunda persona es cuando Smith señala que hay dos formas de juzgar la propiedad de los sentimientos ajenos. Una es cuando el objeto que incita los sentimientos no tiene ninguna relación particular con las partes. Éstos son los juicios de las ciencias o del gusto; juicios teóricos cuyo objeto es "la diversa apariencia que la gran máquina del universo está siempre exhibiendo" (TMS I.i.4.2). ${ }^{11}$ Estos juicios se realizan desde una perspectiva externa y en ellos, dice Smith, no hay necesidad de simpatía; i.e., no se

\footnotetext{
${ }^{10}$ Por ejemplo, entre otras referencias, en El utilitarismo John Stuart Mill afirma que entre la propia felicidad y la de los demás, el utilitarismo exige una estricta imparcialidad, como la de "un espectador desinteresado y benevolente" (cap. 2).

${ }^{11}$ Smith vuelve a recurrir a la metáfora de "la gran máquina [del universo]" refiriéndose al placer que provoca la contemplación del "todo", cuando critica de
} 
requiere concordancia ni mutua aprobación de sentimientos puesto que el objeto juzgado no es vitalmente significativo para ninguna de las partes. El segundo tipo de juicios es cuando el objeto sí afecta a alguna de las partes. Éstos deben estar basados en la simpatía mutua: "Si no te indignas frente al daño que me han hecho, o no lo haces en proporción a mi resentimiento [...] nos volvemos insoportables uno al otro" (TMS I.i.4.5). Se trata de juicios prácticos que nos involucran vitalmente, en los que no podemos renunciar por completo a nuestra autoidentificación. Y los juicios morales, para Smith, pertenecen a este grupo. ${ }^{12}$

Smith constata que todo ser humano tiene un deseo innato de simpatía, el cual en la interacción se manifiesta como un deseo de simpatía mutua. Con esta sola observación, desde el ámbito teórico (espectador externo o en tercera persona), Smith traslada la moral al ámbito de la praxis (espectador participante o en segunda persona). ${ }^{13}$ Los juicios de la ciencia y el gusto no son iguales a los juicios morales, puesto que en los últimos las personas se sienten personalmente comprometidas, están autoidentificadas y ambas partes - agente y espectador - desean el placer de la simpatía mutua; i.e., sentirse aprobados, comprendidos, validados por el otro. Por ello, cada vez que nos sentimos desaprobados "cambiamos imaginariamente de lugar" con el otro para vernos desde sus ojos y poder ajustar nuestros sentimientos a sus expectativas. "Así como la persona principalmente interesada se place en nuestra simpatía [...] así también nosotros parecemos complacidos cuando podemos simpatizar con ella" (TMS I.i.2.6). En consecuencia, junto al deseo de simpatía mutua habrá también "mutua espectatorialidad". En contraste con sus antecesores, para Smith el espectador "entra" a la situación y se convierte en otro agente; mientras que el agente también se transforma en un "espectador del espectador". Ambos son iguales. Y los estándares morales los deben encontrar conjuntamente en su interacción.

manera explícita que la utilidad sea la fuente de la aprobación moral. Véanse TMS IV y TMS VII.iii.3.17.

${ }^{12}$ Ralph Lindgren (1973) ha sido uno de los pocos intérpretes que han reparado en este pasaje; pasaje que, de acuerdo con mi interpretación da la clave epistemológica para comprender la TMS. Lingdren, al primer tipo de juicios los llama "juicios de las ciencias y del gusto", y, al segundo tipo, "juicios de preocupación vital", cuyos objetos tienen "consecuencias prácticas" (pp. 23-24).

${ }^{13}$ Así lo nota McCloskey (2009, p. 18) denunciando un error de Nozick que llama "observador ideal" al espectador imparcial smitheano, y agrega: "Nótese el cambio que provoca el error [...] entre una metáfora humanista del teatro a una metáfora antihumanista de las ciencias empíricas." Es el cambio de una sobreintelectualizada perspectiva de la tercera persona a una perspectiva de la segunda persona. 
Por otro lado, puesto que la simpatía supone una identificación imaginativa, el objeto del juicio también cambia. Los espectadores de Hutcheson y Hume juzgaban cualidades de los agentes expresadas en sus acciones y efectos. El de Smith juzgará la "propiedad" de las pasiones/acciones de un agente concreto en una situación concreta: "La simpatía [...] no surge tanto de la visión de una pasión cuanto de la situación que la provoca" (TMS I.i.1.10). Esto significa que los sentimientos simpatéticos en Smith no dependen del contagio de pasiones sino del contexto en que se sitúa el agente. Haakonssen habla de "propiedad situacional" y dice que Smith convierte la simpatía en un "proceso que mira hacia atrás"; i.e., la virtud no se juzga por los efectos que producen ciertas cualidades de los individuos sino por la aprehensión de la adecuación de la reacción afectiva del agente con los aspectos moralmente relevantes de su situación (Haakonssen 1981, pp. 46-48). ${ }^{14}$ Así, con esta nueva noción de simpatía, Smith impide toda interpretación consecuencialista de su ética.

Otra consecuencia de la simpatía mutua es que se vuelve performativa. En Hutcheson y Hume el espectador "refleja pasivamente los sentimientos de otro"; no participa, está fuera de la situación juzgada ( $c f r$. Fleischacker 2012, p. 277, n.5). En contraste, en Smith tanto el espectador como el agente deben ser activos. Como ambos desean el placer de la simpatía mutua, se proyectan en el otro y se esfuerzan en moderar sus sentimientos hasta un punto de correspondencia en que puedan aprobarse recíprocamente (TMS I.i.3.1). Esto lleva a Smith a agregar un segundo conjunto de virtudes a su ética sentimentalista: las del autodominio o self-command. Smith, en una probable alusión a Hutcheson, afirma que la benevolencia no basta para ser virtuoso: "No es el suave poder de la humanidad, la débil llama de benevolencia que la Naturaleza encendió en el corazón humano, la que es capaz de contrarrestar nuestros impulsos más fuertes de autointerés" (TMS III.3.4). Hume también lo había advertido, pero su solución fue corregir esa parcialidad por medio de la perspectiva general del espectador externo ( $\operatorname{Tr} 3.2 .2 .13)$; perspectiva imparcial en cuanto es de todos y de nadie a la vez. La novedad de Smith es que este "elemento correctivo" —imparcialización de los sentimientos por medio del self-command - es incorporado en el mismo proceso simpatético, introduciendo un factor de racionalidad en el núcleo de la simpatía con la que el espectador evalúa ( $c f r$. Fleischacker 2012,

\footnotetext{
${ }^{14}$ Fleischacker habla del "placer que causa una respuesta emocional correcta" (2012, p. 302) y Darwall lo explica como los sentimientos "avalados" por los aspectos de la situación a los que responden (1998, p. 268).
} 
p. 275). McHugh señala que: "En contraste con Hume, que emplea la simpatía para explicar [...] la posibilidad del juicio moral, en [la ética de] Smith su teoría de la simpatía [imparcializada] se identifica con su teoría del juicio moral" (2011, p. 191). En Smith, el sentimiento y la razón cooperan en el propio origen del juicio moral. La razón no es auxiliar ni meramente técnica, no cumple un papel secundario a los sentimientos. Por el contrario, "Smith destaca la racionalidad inherente a la vida ordinaria, que la configura desde adentro, corrigiéndola cuando es necesario con sus mismas herramientas, en lugar de intentar justificarla o criticarla desde un punto de vista externo" (Fleischacker y Brown 2010, pp. 3-4). La identificación simpatética encapsula sentimientos y razón, simpatía e imparcialidad, volviéndolos como el cara y el sello del juicio moral y acercando su teoría hacia una ética de la razón práctica. ${ }^{15}$

\subsection{Espectador interno}

El ingreso de la razón en su ética sentimentalista es ilustrado por Smith a través de la internalización del espectador imparcial (Fricke 2013, p. 186; Sayre-McCord 2010, p. 129; McHugh 2011, pp. 196197). Dado el deseo de simpatía mutua, cuando un agente se percata de que sus afectos parciales innatos no son aprobados por sus pares, "sale de sí mismo" para verse a través de esos otros ojos y caer en la cuenta de que, desde esa perspectiva, él no es más que uno en una multitud de iguales (TMS II.ii.2.2). Por ello, si no restringe su parcialidad con la virtud del self-command, jamás obtendrá su aprobación ni el placer de la simpatía mutua. Este autodistanciamiento para verse como si fuera su propio espectador, esta vuelta reflexiva o el imaginarse cómo lo vería un espectador indiferente, lo introduce en la "gran escuela del self-command" (TMS 3.3.22) donde - tras la práctica continua de este ejercicio de la imaginación - termina internalizando al espectador imparcial imaginario (aprende a poner momentáneamente entre paréntesis sus propios intereses) y actuando y juzgando como él lo haría.

La internalización del espectador imparcial es la que rompe la dicotomía del juez externo frente a un "todo" conformado por agentes no identificados. Smith rechaza ese modelo señalando que las cualidades morales no son observables desde fuera. Los sentimientos morales surgen de la aprehensión de la propiedad de las pasiones/acciones de agentes concretos en circunstancias concretas. La propiedad no es imperceptible para quienes participan de la situación, a pesar de que

${ }^{15}$ Véase Carrasco 2004. 
—dice Smith - sí resulta indefinible (TMS VI.ii.1.22). Es decir, lo apropiado para cada contexto particular no es un criterio que se pueda formular en una definición universal; no es posible capturarlo desde una perspectiva externa, impersonal, sin haberse identificado con el agente y su situación. Lo que "la situación merece" cambia de acuerdo con las circunstancias. Ésta es la razón por la cual la perspectiva newtoniana del espectador en tercera persona, aunque pueda ser adecuada para el ámbito teórico, no es capaz de dar razón de los sentimientos y juicios morales.

Para Hume, la perspectiva imparcial requería situarse en un "punto de vista general" (Tr 3.3.1.23). Smith no concuerda y afirma precisamente que: "Cuando consideramos la virtud y el vicio de modo abstracto y general, las cualidades que excitan [los] sentimientos [morales] tienden a desaparecer" (TMS IV.2.2). De hecho, dice que no detestamos el vicio por el daño (desutilidad) que podría causar al todo, sino que si detestamos el vicio es porque es detestable, nada más, y no necesitamos inventarnos razones para justificar ese rechazo (TMS II.ii.3.8). La diferencia, explica Fleischacker, es que "la teoría de Smith [...] ayuda a comprender cómo el impulso al juicio moral puede insertarse dentro de los procesos naturales de nuestra afectividad, más que ser generado desde un punto de vista externo, como sucede con Hume [y Hutcheson]" (2012, p. 293).

Por consiguiente, la imparcialidad del espectador smitheano no procede de la perspectiva general de quien mira desde fuera a agentes no identificados y les asigna el mismo valor. En la TMS el espectador se coloca en una posición de segunda persona, se identifica con el agente en el momento de juzgar. Y, como la imparcialidad en esta ética es indiscernible de la identificación simpatética, no es posible que el objeto del juicio sean cualidades/acciones/pasiones de "agentes sin rostro". En Smith, la imparcialidad no se obtiene gracias a una completa abstracción del contexto, sino que, dice Darwall, la imparcialidad regula los juicios morales "disciplinando el modo como entramos en la perspectiva del agente [...] y no proveyendo su propia perspectiva. El juicio moral implica una proyección imparcial dentro del agente" (Darwall 1999, p. 142). En otras palabras, en el juicio moral el espectador lejos de proyectarse dentro del otro como sí mismo (autoidentificado) lo hace como si fuera un espectador imparcial, con una simpatía ya imparcializada, lo que se posibilita a través de la mirada de una tercera instancia (el espectador imaginario) capaz de corregir los sesgos propios de quienes participan en primera persona. Los sentimientos de quien realiza el juicio moral ya 
fueron moderados, modulados e informados por la razón en "la gran escuela del self-command". En la ética de Smith no des/aprobamos moralmente con base en nuestros sentimientos innatos, parciales y espontáneos, juzgamos con los sentimientos morales que son de segundo orden, puesto que son nuestros propios sentimientos pero ya informados por "el principio, la conciencia, la razón, el habitante de nuestro pecho" (TMS III.3.4); i.e., los sentimientos que tendría un espectador imparcial.

Otra gran diferencia entre las éticas de Hutcheson/Hume y la de Smith es que el último, al incorporar el "elemento correctivo" dentro del proceso simpatético permite que, manteniendo su función constitutiva de los sentimientos en el proceso de justificación moral, deje también espacio a una justificación racional. Los juicios morales, para Smith, son aquellos de los que podemos dar cuenta. Esto demuestra, como Amartya Sen ha destacado, que en los orígenes de la modernidad la perspectiva de Smith ya preanunciaba que: "No existe un conflicto irreductible [...] entre la razón y los sentimientos, y hay buenas razones para dar espacio a la relevancia de los sentimientos [tanto como a la razón], en los juicios" (2009, p. xvii). A diferencia de sus contemporáneos, en la ética de Smith sentimientos y razón entran a la par y armoniosamente en la realización del juicio moral.

Entonces, al hacer el juicio moral proyectándose en el agente como si fuera un espectador imparcial (McHugh 2011, p. 190), el punto de propiedad vendrá dado por la coincidencia con los sentimientos de un espectador imparcial -i.e., sentimientos que al estar ya modulados por la razón pueden establecer lo que sería la respuesta emocional correcta para una situación determinada - y no por la simpatía mutua o la coincidencia de los sentimientos subjetivos de dos actores parciales. Y como agente y espectador adecuan sus sentimientos al mismo estándar, su juicio debería coincidir. ${ }^{16}$

Por ende, gracias a la internalización del espectador los juicios morales en Smith pueden desligarse de la aprobación contingente de observadores externos y obtener una medida interna de aprobación

\footnotetext{
${ }^{16}$ Se podría distinguir entre la "simpatía psicológica" y la "simpatía moral". La primera es cuando me proyecto como yo misma dentro del agente y evalúo de acuerdo con mis criterios subjetivos (sesgados por vínculos afectivos, etc.). La segunda estaría ya informada por la razón y es a la que Darwall alude. La diferencia se ve, por ejemplo, cuando algún amigo nos cuenta que dañó a un tercero quien, sabemos, le ha causado mucho sufrimiento. En este caso solemos tomar partido por nuestro amigo. Sin embargo, y simultáneamente, también somos capaces de tomar distancia y evaluar si esa acción era o no adecuada (proporcionada) para la situación. De este modo podríamos perfectamente decir: "Yo entiendo tu reacción, pero no puedo justificarla" ( $c f r$. Carrasco 2011, p. 18).
} 
con su propio criterio normativo. ${ }^{17}$ Desde el deseo psicológico de la simpatía mutua que nos impulsa a esa "vuelta reflexiva" que implica mirarnos desde fuera y vernos como uno en una multitud de iguales, Smith va explicando el proceso psicológico que hace posible el surgimiento de la conciencia moral. Así, aunque el espectador imparcial sea originalmente un producto social (en cuanto se origina en la interacción), tras su internalización las convenciones son menos importantes que la imaginación para el juicio (Raphael 2007, pp. 14-15). ${ }^{18}$ Ahora el espectador soy yo misma quien, al removerme imaginariamente de mi posición céntrica innata, adquiero la distancia necesaria para juzgar con imparcialidad. Smith descubre así que no se requiere estar "fuera" (punto de vista externo) para ser imparcial. Las personas podemos tomar distancia, poner temporalmente entre paréntesis nuestra autoidentificación (los propios intereses, sesgos, etc.) para hacer un juicio moral -incluso cuando nos juzgamos a nosotros mismos-. De hecho, cuando nos autoevaluamos nos dividimos en un "yo juez" (el espectador imparcial) y un "yo juzgado" (yo autoidentificado), y el espectador puede juzgar y sentenciar respecto de las propias acciones (TMS III.1.6). Esta descripción expone con claridad cómo el "espectador imparcial interno" no coincide con el agente, no tiene idénticas pasiones ni sesgos. La "tercera instancia" que para los ilustrados escoceses garantizaba la imparcialidad se conserva en Smith, pero es internalizada y se transforma en aquellos patrones habituales de deliberación que median en nuestros juicios morales, en la propia conciencia.

\section{Imparcialidad, impersonalidad y dignidad}

Tal como la posición de un espectador en tercera persona genera una estructura metaética dicotómica, la de un espectador en segunda persona genera otra que se podría llamar la de una "ética de la

${ }^{17}$ Un excelente análisis del juicio del espectador imparcial en cuanto estándar de la moralidad de las pasiones/acciones se encuentra en Sayre-McCord (2010). Allí muestra la perfectibilidad de este estándar, la importancia de no desligarse de los espectadores externos que siempre cumplirán la función de contraste para una conciencia rectamente formada, etcétera.

${ }^{18} \mathrm{La}$ conciencia en Smith no es la voz de los espectadores externos internalizada, como un superego. Se da un proceso de "desligarse" de los espectadores externos que, sin embargo, no es nunca total ni tampoco sería deseable que lo fuera. Según Smith, el espectador externo debe "despertar" al interno cuando éste se aleja de la realidad y se arriesga al autoengaño (TMS III.3.41). Pero la conciencia tiene una capacidad crítica y reflexiva que le permite independizarse, aunque nunca dar la espalda, de la opinión social. Véanse McHugh 2011, pp. 196-198 y el análisis de Fricke (2013). 
segunda persona". El simple cambio de posición de la figura del espectador imparcial que introduce Smith en su ética espectatorial transforma irreversiblemente el carácter de su teoría y repercute tanto en el objeto y justificación del juicio como en lo que se entenderá por el concepto de imparcialidad: el igual respeto a la dignidad de cada persona.

Aunque estas distinciones no se habían sistematizado en tiempos de la Ilustración escocesa, hace algunas décadas Peter Strawson realizó un análisis que resulta muy útil para entender las profundas diferencias que se encuentran entre distintas éticas construidas desde la perspectiva de un espectador. Strawson fue de los primeros filósofos contemporáneos en reivindicar la importancia de los sentimientos en las actitudes morales y en cómo éstas dependen de nuestras respuestas afectivas frente a la conducta de los demás (Strawson 1974, p. 6). $\mathrm{Su}$ descripción de las diversas actitudes reactivas provocadas por la interacción no sólo permite afinar la comprensión de los sentimentalismos-espectatoriales escoceses, sino también explicar por qué una de las posiciones del espectador genera una estructura metaética que favorece el utilitarismo y un concepto de imparcialidad que lleva a la impersonalidad; mientras la otra impide una moral utilitarista y cambia el significado del concepto de imparcialidad.

En concreto, Strawson dice que cuando vemos al otro como alguien "completamente responsable" adoptamos una actitud participativa respecto de él, significando que reaccionaremos a su buena/mala voluntad sobre nosotros (Strawson 1974, pp. 6-10). Ésta sería, en terminología de Darwall, una "relación yo-tú", que expresa un tipo de vínculo entre las personas que está basado en el reconocimiento mutuo, una relación en segunda persona en que "veo al otro como un 'tú' y lo veo como teniendo la misma relación conmigo" (Darwall 2006 , p. 43). La relación yo-tú implica la conciencia mutua de cierta igualdad, puesto que al identificarme con el otro o proyectarme en él, estoy reconociendo que el otro tiene su propia perspectiva, independiente de la mía. Y si simultáneamente busco y otorgo aprobación al otro, es porque también respeto su facultad de juicio, su capacidad de decidir y actuar de una u otra forma (Sayre-McCord 2010, pp. 194 y 198). Reconozco a un igual, alguien a quien por "la autoridad que le confiere la capacidad de autodirigirse" (Darwall 1999, p. 154) - o en términos de Smith, la dignidad propia de las personas como seres capaces de self-command- se le pueden exigir determinadas respuestas; tal como él, dada mi capacidad de autodirección, tiene también la autoridad para exigírmelas. Las relaciones en segunda per- 
sona son relaciones que implican un R.S.V.P. (Darwall 2006, p. 40). Nos dirigimos al otro reconociendo nuestra autoridad recíproca para exigirnos determinadas actitudes: actitudes que expresen respeto. ${ }^{19}$

Por contraste, cuando no vemos al otro como un ser "completamente responsable" - afirma Strawson - tenemos otras expectativas. Lo miramos desde fuera, como se observa a un objeto, y adoptamos una actitud objetiva hacia él. Se trata de una "relación yo-eso", como la denomina Darwall, que no es sólo la que tenemos con objetos sino también, por ejemplo, la que adoptamos frente a niños o dementes, o la que asumimos cuando de manera temporal debemos tomar una distancia científica frente a los otros para concentrarnos en establecer "cómo funcionan" (e.g., en la relación médico-paciente o en el diseño de políticas públicas), cuando se ve al otro como algo que debe ser medido, administrado o curado de un modo eficiente (Strawson 1974, p. 12). Sin ser antinatural, esta posición no es nuestra postura habitual en la vida. Es una abstracción. Ordinariamente estamos involucrados con los demás, en relación con (y no observando a) los otros.

Este análisis concuerda de modo sorprendente con la distinción que hacía Smith entre los distintos tipos de juicios - los que requieren y los que no requieren simpatía mutua - así como con la razón que él esgrimía al respecto: sentirse o no involucrado en la situación. ${ }^{20}$ La actitud que Strawson llama objetiva equivaldría a la que adopta un observador en tercera persona, el que mira desde fuera y no se involucra con el otro. La que Smith declaraba propia de los juicios de las ciencias y el gusto. La actitud participativa, en cambio, es la del espectador en segunda persona, la de quien está en una relación yo-tú, vitalmente involucrado y al que le afectan las reacciones del otro. Para Smith, la del espectador que busca y se esfuerza por obtener el placer de la simpatía mutua.

Ahora bien, desde la perspectiva del espectador en tercera persona la imparcialidad significa considerar a todos por igual. El respeto

${ }^{19}$ Darwall es más específico y habla de "respeto de reconocimiento", entendiendo por él el modo en que regulamos nuestra conducta respecto del otro en virtud de las restricciones que asumimos debido a que es un igual, una persona. Este respeto no se refiere a la actitud de estima que se puede tener por alguien en virtud de tal o cual cualidad. Es el respeto a la igual dignidad; el reconocimiento de la recíproca autoridad que nos tenemos en cuanto somos recíprocamente responsables frente al otro: debemos, mutuamente, "darnos cuentas" (somos, dice Smith, accountable beings). Véase Darwall 2010, p. 108.

${ }^{20}$ Muchas veces es necesario observar a otras personas como "ésos" para ser sanados, enseñados, etc. Esta mirada no es denigrante en sí misma. Lo que sí violaría la dignidad del otro es no volver nunca a la mirada de un "tú". 
a una igualdad formal entre los agentes previene arbitrariedades. Sin embargo, esta imparcialidad propia de la actitud objetiva puede con facilidad deslizarse hacia la impersonalidad o desidentificación de los agentes que son mirados como objetos (actitud objetiva) y, en este sentido cuantificables e intercambiables. El modelo ético que el espectador en tercera persona genera induce a ver a los sujetos morales como "agentes sin rostro".

Mas si, como dice Smith en la vida moral nos sentimos "vitalmente involucrados", si vivimos en relación con - no observando a- los otros, la moral es uno de esos ámbitos en los que resulta imposible "sacarnos el rostro"; somos incapaces de prescindir completamente de nuestra autoidentificación. ${ }^{21}$ Por eso la perspectiva del espectador en tercera persona no es adecuada para esta esfera, y el proyecto de buscar el garante del juicio imparcial en un espectador newtoniano no es plausible.

Pero esto no significa que la figura del espectador imparcial no sea útil en la teoría ética. Un espectador en segunda persona también garantiza imparcialidad, aunque en este caso no sea entendida como mero respeto a una igualdad formal. Los nuevos estudios de la teoría de Smith han desvelado otro tipo de imparcialidad, una "imparcialidadsimpatética" que en cuanto incluye la identificación del espectador con el agente imposibilita la despersonalización de los individuos. La identificación hace que el espectador sienta lo que le pasa al otro como si le pasara a él mismo: al presenciar una injusticia, por ejemplo - $\mathrm{O}$ al ver que un igual es tratado como un inferior (TMS II.ii.2.2) la indignación del espectador surge de modo espontáneo, como si la víctima hubiera sido él ( $c f r$. TMS II.i.2.5).

Luego puede haber un "pensamiento posterior" (TMS I.i.4.4) sobre la desutilidad global de las acciones injustas, pero la utilidad no es la fuente de nuestra des/aprobación ya que las cualidades que excitan los sentimientos morales — como decía Smith - son originaria y esencialmente distintas de esa percepción (TMS IV.2.3). Las prácticas moralmente apropiadas pueden ser convenientes para la vida social; pero el sentimiento de aprobación no surge debido a esa conveniencia. Éste sería el error de Hume. La utilidad también puede "avivar" nuestra aprobación (TMS IV .2.3), pero no es su fuente. Si detestamos la injusticia es, simplemente, porque es detestable, porque en nuestras relaciones cotidianas las personas nos exigimos respeto mutuo y,

${ }^{21}$ Por ejemplo, si sólo puedo salvar a un niño de los dos que se ahogan. Uno es mi hijo y el otro un desconocido. Sea cual sea la determinación final, nadie es capaz de simple y fríamente realizar una cuantificación objetiva de los méritos de cada niño para tomar la decisión. 
en este caso, el agresor denigró a alguien que no merecía ser tratado así. Nos irrita ese absurdo amor propio que le hace sentirse superior a los demás y tratar a sus iguales como si fueran inferiores (TMS II.iii.1.5). Esto, y nada más, es lo que hace detestable a la injusticia.

La identificación simpatética o la del espectador en segunda persona nos hace tomar conciencia del respeto que nos debemos mutuamente. Por ello, a diferencia de Hutcheson y Hume, al espectador en segunda persona, al que puede identificarse con los demás, le importa el individuo antes que la sociedad (TMS II.ii.3.10), la parte antes que el todo; de modo que su concepto de imparcialidad significa el reconocimiento de la igual dignidad de cada individuo particular. Cuando Smith afirma que el deseo de simpatía y "los sentimientos de aprobación y desaprobación son las pasiones más vigorosas de la naturaleza humana" (TMS V.2.1) alude a esta exigencia de respeto de reconocimiento sobre la que se funda la moral. Haakonssen explica que si reaccionamos con indignación cuando alguien es tratado injustamente, es porque sentimos que hay algo que se le debió dar pero no le fue dado (1981, p. 86). Este "algo", según mi interpretación, es precisamente el respeto debido a cada individuo singular. En consecuencia, dada la imparcialidad-simpatética una ética de la segunda persona incluye restricciones sustantivas, prohibiciones universales: hay cosas que no se le pueden hacer a la gente.

Por consiguiente, esta noción de imparcialidad difiere de la que se deriva del espectador en tercera persona porque significa respeto a la dignidad de cada individuo, respeto que no puede ser sobrepasado por ninguna cantidad de bien, utilidad o interés social. Es imparcial en cuanto todo individuo debe ser respetado por igual, no caben excepciones. Pero no es impersonal, porque el respeto se otorga a un sujeto "con rostro", i.e., una persona concreta en quien reconocemos a un igual que nos exige respeto. En una ética fundada sobre relaciones de segunda persona, imparcialidad no es ni impersonalidad ni simple igualdad; sino que, necesariamente, es una imparcialidad con contenido: es el igual respeto exigible y exigido por la dignidad de cada ser humano.

\section{Espectador en segunda persona y sus ecos contemporáneos}

La clave de la ética de la segunda persona que lleva a que la imparcialidad signifique "respeto a cada individuo", es que el juicio sea justificado desde abajo, o desde dentro (bottom-up approach) de la misma comunidad moral (Fricke 2013, p. 177). Éste ha sido un elemento que ha atraído en particular la atención de los autores contemporáneos, 
puesto que - a diferencia de los principales sistemas modernoslos estándares morales de una ética de la segunda persona (como la TMS) no están definidos a priori ni son externos a la comunidad. Lo "apropiado" se debe encontrar en un esfuerzo conjunto entre las personas involucradas; un esfuerzo que no termina debido a que la única garantía de haber acertado es someter los juicios a permanente contraste y eventual refutación (Sayre-McCord 2010, p. 129).

Cuando una norma moral está justificada desde la perspectiva de la tercera persona apela a razones objetivas para la des/aprobación de determinada pasión/acción. Estas razones pueden ser perfectamente racionales, pero no mueven a la acción puesto que las personas no somos sólo racionales. Las razones objetivas, como la utilidad en Hume o el "mayor bien para el mayor número" de Hutcheson, son un pensamiento posterior; son abstraídas de la praxis pero carecen de fuerza vinculante. La moral es concreta y particular, implica relaciones y reacciones entre agentes reales en comunidades reales. Los sentimientos morales se sienten obligatorios porque surgen de esas relaciones participativas (no impersonales, no objetivas como diría Strawson) entre los agentes, las cuales nos involucran vitalmente.

Otra característica, que se relaciona con la anterior y que es propia de esta estructura, es la intersubjetividad (Fricke 2012, pp. 217-238). La moral es interactiva desde su origen. Los sentimientos morales surgen desde la perspectiva de la segunda persona o cuando nos relacionamos con los otros como seres responsables y capaces de dar cuenta de su propia conducta. Estos sentimientos siempre hacen referencia a otros. Nadie culpa a un árbol, por ejemplo, por caer sobre su casa. Sólo culpamos y castigamos a aquellos que sabemos responsables de sus actos y que hubiesen podido actuar de otro modo. Además, la conciencia moral también se forma y refina en la interacción, en las relaciones con otros (Fricke 2013). Y, por último, esta intersubjetividad conlleva, en sí misma, un principio de igualdad. Es decir, toda relación se inicia con al menos una presunción de igualdad entre las partes. Nadie intenta simpatizar (proyectarse en, identificarse) con quien no considera, al menos en principio, un igual.

Asimismo, en una ética de la segunda persona, y a diferencia de las éticas predominantes en la modernidad, se considera el contexto en los juicios morales, o lo que se denomina "apreciación situacional". Una ética que juzga haciendo abstracción del dónde/cuándo/quién de la acción no puede dar respuestas satisfactorias en todo tiempo y lugar. Las circunstancias y particularidades de los agentes y situaciones importan, y deben tomarse en cuenta para juzgar con propiedad. 
Pero esto no supone relativismo ni arbitrariedad. Los juicios son imparciales, aunque es una imparcialidad "con rostro", distinta de la impersonalidad utilitarista. El elemento de racionalidad que se incluye en la identificación simpatética garantiza que cualquier persona, juzgando como lo haría un "espectador bien informado, simpatético e imparcial" (TMS VII.ii.1.49), o cualquier persona poniendo temporalmente entre paréntesis sus propios sesgos y singularidades, tendría que llegar al mismo juicio.

Así, aunque los tres ilustrados escoceses buscaron la garantía del juicio imparcial en una tercera instancia desinteresada, la peculiar posición del espectador imparcial de Smith cambia el carácter de su sentimentalismo-espectatorial. Smith crea una estructura metaética "de la segunda persona", donde la virtud deja de ser una cualidad predefinida y medible de manera impersonal, y se identifica con la acción/pasión apropiada para una situación particular según lo descubren los participantes en conjunto. Sin un espectador externo se disuelve la estructura dicotómica y se evita que una ética se deslice hacia el utilitarismo moral. De igual forma, sin el espectador externo la imparcialidad en el ámbito moral no es igual a la imparcialidad en el ámbito teórico. La imparcialidad no puede ser impersonalidad porque hay un momento en el juicio en el que es imposible suspender la autoidentificación. La imparcialidad, más bien, es el igual respeto a la dignidad de cada ser humano.

En síntesis, la posición desde la que juzga el espectador sería, en última instancia, la que explicaría por qué desde una ética espectatorial pueden desprenderse teorías contrapuestas con sus respectivas comprensiones de un juicio moral imparcial: una que puede ser ilustrada con los protoutilitarismos de Hutcheson y Hume; y la otra representada en la ética de Adam Smith, una "ética de la segunda persona" que, con sus novedosas características, se empieza a ver como una alternativa a los paradigmas éticos modernos. Así sugiere Amartya Sen al afirmar que la filosofía de Adam Smith "puede todavía contribuir mucho al pensamiento económico, político y moral de nuestros días" (2013, p. 592). Según lo que aquí he propuesto, la posición del espectador imparcial es la característica crucial para su renovada actualidad.

*Agradezco al proyecto Fondecyt 1120381, así como al Centre for the Study of Mind and Nature (CSMN), de la Universidad de Oslo, por su acogida durante una estadía de investigación. 


\section{BIBLIOGRAFÍA}

Blackstone, W.T., 1965, Francis Hutcheson and Contemporary Ethical Theory, University of Georgia Press, Georgia.

Broadie, A., 2006, "Sympathy and the Impartial Spectator", en K. Haakonssen (comp.), The Cambridge Companion to Adam Smith, Cambridge University Press, Nueva York, pp. 158-187.

—_, 2003, "The Human Mind and Its Powers", en A. Broadie (comp.), The Cambridge Companion to the Scottish Enlightenment, Cambridge University Press, Cambridge.

Carrasco, M.A., 2011, "From Psychology to Moral Normativity", The Adam Smith Review, vol. 6, pp. 9-29.

- - 2004, "Adam Smith and the Modern Reconstruction of Practical Reason", The Review of Metaphysics, vol. 58, no. 1, pp. 81-116.

Darwall, S., 2010, "Smith Ambivalence about Honour", The Philosophy of Adam Smith. The Adam Smith Review, vol. 5, pp. 106-122.

-, 2006, The Second-Person Standpoint, Harvard University Press, Cambridge.

—_, 2004, "Equal Dignity", The Adam Smith Review, vol. 1, pp. 129134.

- 1999, "Sympathetic Liberalism. Recent Work on Adam Smith", Philosophy and Public Affairs, vol. 28, no. 2, pp. 139-164.

- 1998, "Empathy, Sympathy, Care", Philosophical Studies, vol. 89, no. 2-3, pp. 261-282.

- 1997, "Hutcheson on Practical Reason", Hume Studies, vol. 23, no. 1, pp. 73-90.

Debes, R., 2007a, "Humanity, Sympathy and the Puzzle of Hume's Second Enquiry", British Journal for the History of Philosophy, vol. 15, no. 1, pp. 27-57.

—_ 2007b, "Has Anything Changed? Hume's Theory of Association After the Treatise", British Journal for the History of Philosophy, vol. 15, no. 2, pp. 313-338.

Fleischacker, S., 2012, "Sympathy in Hume and Smith: A Contrast, Critique and Reconstruction", en C. Fricke y D. Follesdal (comps.), Intersubjectivity and Objectivity in Adam Smith and Edmund Husserl, Ontos Verlag, Alemania, pp. 273-311.

Fleischacker, S. y V. Brown (comps.), 2010, "Introduction”, The Philosophy of Adam Smith. The Adam Smith Review, vol. 5, pp. 1-11.

Frazer, M., 2010, The Enlightenment of Sympathy, Oxford University Press, Nueva York.

Fricke, C., 2013, “The Sympathetic Process and the Origin and Function of Conscience", en C. Berry, M.P. Paganelli y C. Smith (comps.), The Oxford Handbook of Adam Smith, Oxford University Press, Oxford, pp. 177-200. 
Fricke, C., 2012, “Overcoming Disagreement - Adam Smith and Edmund Husserl on Strategies of Justifying Descriptive and Evaluative Judgments", en C. Fricke y D. Follesdal (comps.), Intersubjectivity and Objectivity in Adam Smith and Edmund Husserl, Ontos Verlag, Alemania, pp. 171-241.

Griswold, C., 1999, Adam Smith and the Virtues of Enlightenment, Cambridge University Press, Nueva York.

Haakonssen, K., 1981, The Science of a Legislator, Cambridge University Press, Cambridge.

Hume, D., 2007, A Treatise on Human Nature, D.F. Norton y M.J. Norton (comps.), Oxford University Press, Oxford.

Hutcheson, F., 2007, A Short Introduction to Moral Philosophy, L. Turco (comp.), Liberty Fund, Indianápolis.

—_ 2005, A System of Moral Philosophy, D. Carey (ed.), Continuum International Publishing Group, Reino Unido.

- 2004, An Inquiry into the Original of our Ideas of Beauty and Virtue, W. Leidhold (comp.), Liberty Fund, Indianápolis.

- 2002, An Essay on the Nature and Conduct of Passions and Affections, with Illustrations on the Moral Sense, A. Garrett (comp.), Liberty Fund, Indianápolis.

Lingdren, R., 1973, The Social Philosophy of Adam Smith, Martinus Nijhoff, La Hague.

McCloskey, D., 2009, "Adam Smith: The Last Virtue Ethicist", en J. Young (comp.), The Elgar Companion to Adam Smith, Edward Elgar, Cheltenham, pp. 3-24.

McHugh, J., 2011, "Relaxing a Tension in Adam Smith's Account of Sympathy", The Journal of Scottish Philosophy, vol. 9, no. 2, pp. 189204.

Norton, F. y M. Kuehn, 2006, "The Foundations of Morality", en K. Haakonssen (comp.), The Cambridge History of Eighteenth-Century Philosophy, Cambridge University Press, Cambridge.

Raphael, D.D., 2007, The Impartial Spectator, Oxford University Press, Nueva York.

—_, 1972-1973, "Hume and Smith on Justice and Utility", New Series, Proceedings of the Aristotelian Society, vol. 73, pp. 87-103.

Sayre-McCord, G., 2010, "Sentiments and Spectators: Adam Smith's Theory of Moral Judgments", The Philosophy of Adam Smith. The Adam Smith Review, vol. 5, pp. 124-144.

Sen, A., 2013, "The Contemporary Relevance of Adam Smith", en C. Berry, M.P. Paganelli y C. Smith (comps.), The Oxford Handbook of Adam Smith, Oxford University Press, Oxford, pp. 581-592. , 2009, The Idea of Justice, Harvard University Press, Cambridge.

Sen, A. y B. Williams, 1982, Utilitarianism and Beyond, Cambridge University Press, Cambridge. 
Slote, M., 1985, Common-Sense Morality and Consequentialism, Routledge and Kegan Paul, Londres.

Smith, A., 1982, The Theory of Moral Sentiments, D.D. Raphael y A. Macfie (comps.), Liberty Fund, Indianápolis.

Strawson, P.F., 1974, "Freedom and Resentment", en Freedom and Resentment and Other Essays, Mathven, Londres, pp. 1-25.

Recibido el 31 de octubre de 2013; aceptado el 12 de mayo de 2014. 